\title{
Relationship between Degree of Exercise Participation and Active Aging among Older Adults
}

\author{
Yung-Tzung Chang, ${ }^{1}$ Chen-Wei Yu, ${ }^{1}$ Cheng-Min Chao $\mathbb{D}^{2}{ }^{2}$ and Rueg-Juen Chen ${ }^{1}$ \\ ${ }^{1}$ Department of Family Medicine, Taoyuan Armed Force General Hospital, Taiwan, China \\ ${ }^{2}$ Department of Business Administration, National Taichung University of Science and Technology, Taiwan, China \\ Correspondence should be addressed to Cheng-Min Chao; g9521807@gmail.com
}

Received 7 June 2020; Revised 18 March 2021; Accepted 30 March 2021; Published 16 April 2021

Academic Editor: Carol J. Burns

Copyright (c) 2021 Yung-Tzung Chang et al. This is an open access article distributed under the Creative Commons Attribution License, which permits unrestricted use, distribution, and reproduction in any medium, provided the original work is properly cited.

\begin{abstract}
Government departments and scholars have focused on promoting health care for older adults in response to population aging and the annual increase in the number of older adults. Old age does not necessarily involve rapid health decline, fragility, or senility. Therefore, active aging among older adults has become a major consideration worldwide. The effect of exercise participation and social support on active aging warrants investigation. This study proposes a conceptual model for understanding the effects of exercise participation and social support on active aging among older adults. Exercise participation, social support, and health literacy were integrated to hypothesize a theoretical model of active aging among older adults. Furthermore, the moderating role of health literacy in the relationship between exercise participation, social support, and active aging was analyzed. Questionnaires were administered to respondents from Northern Taiwan during face-to-face interviews. Of the 1,800 distributed questionnaires, 1,586 completed questionnaires were received (response rate $=88.1 \%$ ). The data collected were analyzed using structural equation modeling. The results indicated that exercise participation $(\beta=0.163, p=0.000)$, social support $(\beta=0.384$, $p=0.000)$, and health literacy $(\beta=0.360, p=0.000)$ had significant positive effects on active aging. Health literacy did not moderate the effects of exercise participation and social support on active aging among older adults $(\beta=-0.054, p=0.197$ and $0.061, p=0.066)$. The current results confirm that social support has a considerable effect on active aging, which could be used as a reference for future proposals targeted at relevant institutions and older adults.
\end{abstract}

\section{Introduction}

Rapid population aging is a common and global phenomenon. Taiwan's demographic structure is changing because of subreplacement fertility and population aging. In 1993, older adults comprised $>7 \%$ of the total population of Taiwan, indicating that the country was becoming an aging society. Furthermore, the proportion of older adults is estimated to exceed $20 \%$ by 2025 , and Taiwan would thus become a super-aged society [1]. Taiwan will face challenges associated with population aging, such as increases in disease burden and disability risk, burdens to the national health care system, decline in the labor force, and heavy financial burdens on the economic security system for older adults. Proposing effective response measures to address the severe health problems among older adults is thus imperative. The
United Nations has proposed concepts, such as active aging and successful aging, that would provide more comprehensive care services for older adults and help them adapt to the aging process so that they can enjoy their later years of life. These proposals have increased the attention on topics related to active aging.

The World Health Organization (WHO) proposed the concept of active aging and relevant policies in response to the challenges presented by population aging. The WHO defines active aging as "the process of optimizing opportunities for health, participation, and security to enhance the quality of life as people age" [2]. The WHO further stresses that the concept of active aging is based on the concept of "successful aging" $[3,4]$ and calls for the development of approaches to improve health, enhance social participation, and promote safety, with the ultimate aim of improving 
older adults' quality of life. "Health," "social participation," and "safety" are the three major pillars in WHO's active aging policies $[2,5]$. Scholars have also included "older adult learning" and "activity" as measurement dimensions of active aging.

Exercise is a planned, organized, and repetitive activity, performed to maintain or improve one or more aspects of health and physical fitness [6]. Improving exercise habits can benefit an individual's emotional state [7]. Participating in appropriate leisure activities or sports improves older adults' physiological functionality and delays the aging process. Therefore, exercise is critical in people's lives [8-10]. Lee [10] noted that social support can be generated through social activities and that social support increases older adults' response capability, enhances self-concepts, and improves emotional adaptation during the aging process. Schaefer et al. [11] divided social support into three dimensions: emotional, tangible, and informational [12, 13]. Adequate exercise participation improves an individual's physiological functions and delays the aging process, whereas social support can enhance older adults' emotional adaptation to aging. Therefore, exercise participation and social support may be conducive to the active aging of older adults.

An individual's involvement in preventive health care actions is influenced by numerous external environmental factors and individual factors (e.g., health literacy, which is an influential variant of personal knowledge) [14]. Individual health literacy is strongly correlated with the development and application of health care and disease knowledge [15]; health literacy also directly affects an individual's health status. Insufficient health literacy is associated with poor self-care capability and increased chronic disease morbidity [16]. In addition, health literacy affects individuals' health care service selection [17]; for instance, poor health literacy results in low utilization of preventive health care services $[18,19]$. Therefore, health literacy is a crucial factor affecting individuals' decision to use or not use medical and health care services. Therefore, the present study aimed to determine whether exercise participation, social support, and health literacy moderated or predicted active aging.

In summary, active aging among older adults has become a major consideration globally. The effect of older adults' exercise participation and social support on active aging warrants discussion. The literature does not include a cohesive theory explaining the roles of exercise participation, social support, and health literacy (as a moderator or predictor) on active aging among older adults. Therefore, the present study (1) primary antecedents (exercise participation and social support) of active aging among older adults and (2) whether exercise participation, social support, and health literacy predicted active aging or moderated the relationships. The following research questions were thus investigated: (1) Can exercise participation and social support significantly predict active aging? (2) How does health literacy moderate the effects of exercise participation and social support on active aging? The results of the study could be used as a basis to provide specific suggestions to relevant institutes and older adults.

\section{Methods}

2.1. Research Model. The present study investigated whether exercise participation, social support, and health literacy predict active aging or moderate the relationships. A hypothesized model was constructed using exercise participation and social support as the exogenous variables, active aging as the endogenous variable, and health literacy as the moderator variable. Figure 1 illustrates the proposed path model for the two hypotheses.

2.2. Research Hypotheses. The following hypotheses were proposed.

$\mathrm{H} 1$ : an increase in exercise participation would increase active aging in older adults

$\mathrm{H} 2$ : an increase in social support would increase active aging in older adults

M1: the relationship between exercise participation and active aging would be moderated by the level of health literacy

M2: the relationship between social support and active aging would be moderated by the level of health literacy

2.3. Instrumentation. Data were collected using a two-part questionnaire survey. The responses for items in the first part were given using a 5-point Likert scale-ranging from 1 (strongly disagree) to 5 (strongly agree)-to assess respondents' exercise participation, social support, health literacy, and active aging. The responses for items in the second part involved were given on a nominal scale to obtain information on respondents' demographic characteristics, including gender, age, formal education, health conditions, and perceived difficulty of exercising.

The scales and formulations adopted to evaluate the variables in this study are outlined as follows.

2.3.1. Exercise Participation. The level of exercise participation was calculated using the equation presented by Fox [20]:

Level of exercise participation $=$ exercise frequency $\times($ exercise intensity + exercise duration).

2.3.2. Social Support. A social support scale employed in previous studies $[3,5,10-13]$ was adopted in this study. This scale was adopted because it has been translated into Chinese and demonstrated high reliability for its three subscales: tangible social support (four items), emotional social support (eight items), and informational functions social support (four items).

2.3.3. Health Literacy Scale. A health literacy scale (nine items) employed in previous studies [14-17] was adopted, with slight modifications. 


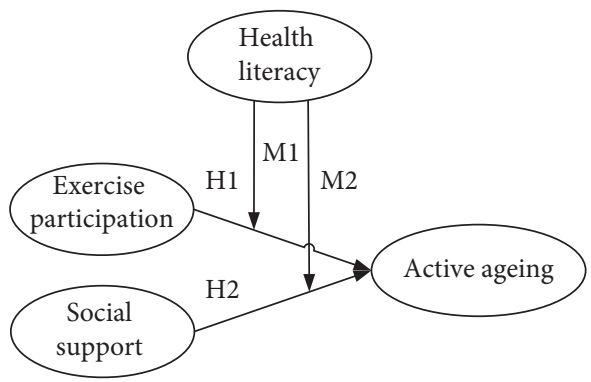

FIgURE 1: Research framework.

2.3.4. Active Aging Scale. An active aging scale (28 items) employed in previous studies [3-5] was used. The scale was translated into traditional Chinese, and high reliability was observed for the five subscales: health (seven items), social participation (six items), safety (five items), older adult learning (five items), and activity (five items).

A pretest, which consisted of administering the questionnaire survey to patients recruited from a target hospital in Taoyuan City through purposive sampling, was performed. In total, 150 pretest questionnaires were distributed, and 104 responses were received. After excluding invalid questionnaires with incomplete or uniform responses, 86 valid responses were obtained; these remaining responses were used for reliability analyses. The results indicated that the Cronbach's alpha for each variable ranged from 0.700 to 0.933, which accords with the suggestions by Hair et al. [21] that a questionnaire scale should have a Cronbach's alpha value of $>0.7$ to be considered reliable. The research variables investigated in the pretest thus exhibited satisfactory reliability.

2.4. Ethical Considerations. All work performed for this study was conducted following the 1964 Helsinki declaration and its later amendments or comparable ethical standards. Furthermore, this study procedure was reviewed and approved by the Institutional Review Board of the Tri-Service General Hospital on February 26, 2018 (1-107-05-018). All respondents were volunteers and were assured that their responses would remain anonymous, their confidentiality would be maintained, and their answers would be used for research purposes only. All respondents provided written informed consent.

2.5. Sample and Descriptive Statistics. The questionnaires were administered to patients at a hospital in Northern Taiwan and a case hospital during face-to-face interviews. A total of 1,800 questionnaires were distributed to medical application system users, selected through convenience sampling. All 1,800 questionnaires were returned; 214 incomplete responses were rejected, leaving 1,586 valid responses for formal data analysis. The response rate thus was $88.1 \%$. Table 1 lists the demographic characteristics of the respondents. The percentages of female and male respondents were $60.4 \%$ and $39.6 \%$, respectively, and about half $(50.8 \%)$ of the respondents were aged 50-59 years. Moreover, $42.7 \%$ of the respondents had an education level of elementary school or below. Furthermore, $45.9 \%$ displayed normal health, and $54.7 \%$ of them reported that they were not tired when exercising.

2.6. Data Analysis. Structural equation modeling was applied to test the research hypotheses and analyze the research model. A two-stage analytical technique was employed following the recommendations of Hair et al. [22] and Anderson and Gerbing [23], which consisted of measurement model assessment (reliability and validity) and structural model assessment (testing the hypothesized relationships and validating the research model). Furthermore, the partial least-squares (PLS) method was employed to analyze the research model. The PLS method was used because it is suitable for large and small sample sizes and for nonnormal data and can be used to analyze both formative and reflective indicators [22].

\section{Results}

3.1. Measurement Model Analysis. Measurement model analyses are typically performed to (1) determine whether the measurement variables in a verification model can be used to accurately measure the latent variables when the overall model is considered and (2) determine the construct validity of the verification model (specifically the discriminant and convergent validity) [23]. Bagozzi and Yi [24] suggested adopting three indicators when assessing measurement models: (1) individual item reliability, (2) composite reliability (CR), and (3) average variance extracted (AVE) [21, 24-26]. Table 2 presents the reliability and validity analysis results for each variable in the present study.

As displayed in Table 2, individual item reliability is primarily used to evaluate the factor loading of measurement variables to latent variables and to verify whether the factor loading of each variable is statistically significant. Hair et al. [21] suggested that the factor loading of research variables should be $>0.6$. The factor loadings of the present research variables were determined to be consistent with this standard [21] and reached significance $(p<0.05)$. Furthermore, the Cronbach's alpha values of the variables were $>0.7$; therefore, the variables were determined to be consistent with the recommendation of Hair et al. [21]. These results indicated acceptable reliability. The CR is primarily used to measure the composition of all variables and represents the internal consistency of the construct indicators. In this study, the CR values of the variables were $>0.6$; based on the standard recommended by Fornell and Larcker [26], the research model thus had satisfactory internal consistency. The AVE is mainly used to calculate the explanatory power of measurement variables for a latent variable. In this study, the AVE values of the variables satisfied the standard suggested by Fornell and Larcker (>0.5) [26], indicating that the research model of this study exhibited satisfactory discriminant validity.

3.2. Hypothesis Testing. Moderation analysis was performed following the recommendations of Baron and Kenny to test 
Table 1: Profiles of respondents $(N=1,586)$.

\begin{tabular}{lcc}
\hline Factor/Level & $N$ & $\%$ \\
\hline Gender & & \\
Male & 621 & 39.6 \\
Female & 947 & 60.4 \\
Age & & \\
$50-59$ & 909 & 50.8 \\
$60-69$ & 450 & 28.7 \\
$\geqq 70$ & 209 & 13.3 \\
Health conditions & & \\
Very well & 60 & 3.8 \\
Well & 586 & 37.4 \\
Ordinary & 720 & 45.9 \\
Bad & 174 & 11.1 \\
Very bad & 28 & 1.8 \\
Formal Education & & \\
Elementary school and below & 669 & 42.7 \\
Junior high school & 406 & 25.9 \\
Senior/vocational high school & 229 & 14.6 \\
College and university & 226 & 14.4 \\
Graduate institute and above & 38 & 2.4 \\
Exercise Perceived & & \\
Not at all tired & 39 & 2.5 \\
Not tired & 858 & 54.7 \\
Somewhat tired & 604 & 38.5 \\
Tired & 63 & 4.0 \\
Very tired & 4 & 0.3 \\
\hline
\end{tabular}

the hypotheses [27]. The moderating role of health literacy was determined according to the significance of the interaction terms in Model 3. In terms of the two hypothesized moderating effects, exercise participation and health literacy (M1) and social support and health literacy (M2) had a nonsignificant effect on active aging $(\beta=-0.054, p=0.197$ and 0.061, $p=0.066$ ). Therefore, M1 and M2 were not supported, and health literacy cannot be considered a moderator of the effects of exercise participation and social support on active aging. Figure 2 presents the moderation analysis results, including the structural path estimates and explained variances.

The structural path analysis of the effects of exercise participation and social support on active aging provided the following results. Exercise participation and social support were a significant determinant of active aging $(\beta=0.163, p=$ 0.000 and $\beta=0.384, p=0.000$ ). Therefore, $\mathrm{H} 1$ and $\mathrm{H} 2$ were supported. Exercise participation, social support, and the interaction explained $49.6 \%$ of the variance in active aging $\left(R^{2}=0.496\right)$. The results also revealed that the proposed model explained a significant proportion of the variation in the endogenous variables. The endogenous variables exhibited strong explanatory power, indicating the model's stability and robustness. Table 3 and Figure 2 present all estimated and standardized path coefficients. Significant paths are indicated with an asterisk. Table 3 also presents the test statistics for the path coefficients.

\section{Discussion}

Government departments and scholars have focused on promoting health care among older adults in response to population aging and the annual increase in the number of older adults. Old age does not necessarily involve a rapid health decline, fragility, or senility. However, the concept of successful aging should not be based on the denial of physiological and psychological functionality losses in old age. Aged society will become a common challenge. Therefore, this study investigated the effects of exercise participation, social support, and health literacy on active aging among older adults. The moderating effect of health literacy on the predictive effects of exercise participation and social support on active aging was investigated. The reliability, validity, path coefficient, and variance explanatory power $\left(R^{2}\right)$ of the proposed research model were all satisfactory. The variance explanatory power $\left(R^{2}\right)$ of the latent variable, namely, active aging, was 0.496 $\left(R^{2}=49.6 \%\right)$. Therefore, the findings indicated that the proposed theoretical framework predicted active aging among older adults.

The results of this empirical study demonstrated that exercise participation and social support exhibited significant and positive effects on active aging. The effect of social support was higher than that of exercise participation. These results accord with those of previous studies $[3,5,7,9,10]$. The connotations of social support based on factors such as availability of emotional support, relevant materials, information, self-esteem, and social companions for older adults were explored. Older adults typically have more free time after retirement than during the earlier periods of their lives. However, relieving older adults of their financial responsibilities for their families results in them no longer playing a crucial role in their families; consequently, older adults may be deprived of opportunities for interpersonal interaction, social life, learning and growth, and self-identification. Older adults can regain a sense of purpose and meaning if they receive emotional and social support or participate in learning and social activities with families and friends. Maintaining interpersonal interactions and participating in meaningful service activities contribute to these effects. Increasing older adults' social participation and promoting social safety can enhance their quality of life, which promotes active aging. Exercise participation is also crucial for active aging among older adults. Positive exercise conditions can improve older adults' emotional states. Appropriate exercise participation can thus enhance physiological functionality and delay the aging process.

Health literacy was investigated as a moderator of the effects of exercise participation and social support on active aging. The results indicated that health literacy had significant positive effects on active aging. However, health literacy did not moderate the relationships between older adults' exercise participation, social support, and active aging. Several reasons could explain these findings. The emphasis on health has increased among older adults because of increased life expectancy. Furthermore, older adults' abilities to acquire, process, and understand basic health information and locate relevant health care services have improved. These changes have resulted in increased basic health literacy among older adults. Furthermore, health literacy has increased older adults' attention to personal health, which has increased active aging. Older 
TABLE 2: Validity and reliability.

\begin{tabular}{|c|c|c|c|c|c|}
\hline Construct & Mean & S.D. & Cronbach's $\alpha$ & AVE & $\mathrm{CR}$ \\
\hline Social support & 3.63 & 0.62 & & & \\
\hline Tangible social support & 3.34 & 0.83 & 0.801 & 0.627 & 0.870 \\
\hline Emotional social support & 3.71 & 0.65 & 0.863 & 0.513 & 0.893 \\
\hline Informational functions social support & 3.76 & 0.73 & 0.820 & 0.652 & 0.882 \\
\hline Active ageing & 3.71 & 0.52 & & & \\
\hline Health & 3.92 & 0.54 & 0.831 & 0.500 & 0.874 \\
\hline Social participation & 3.63 & 0.62 & 0.808 & 0.523 & 0.864 \\
\hline Safety & 3.82 & 0.65 & 0.812 & 0.571 & 0.869 \\
\hline Older adult learning & 3.47 & 0.75 & 0.882 & 0.680 & 0.914 \\
\hline Activity & 3.63 & 0.66 & 0.853 & 0.632 & 0.895 \\
\hline Health literacy & 3.52 & 0.57 & 0.828 & 0.428 & 0.868 \\
\hline
\end{tabular}

Note: S.D. = standard deviation; AVE: average variance extracted; $C R=$ composite reliability.

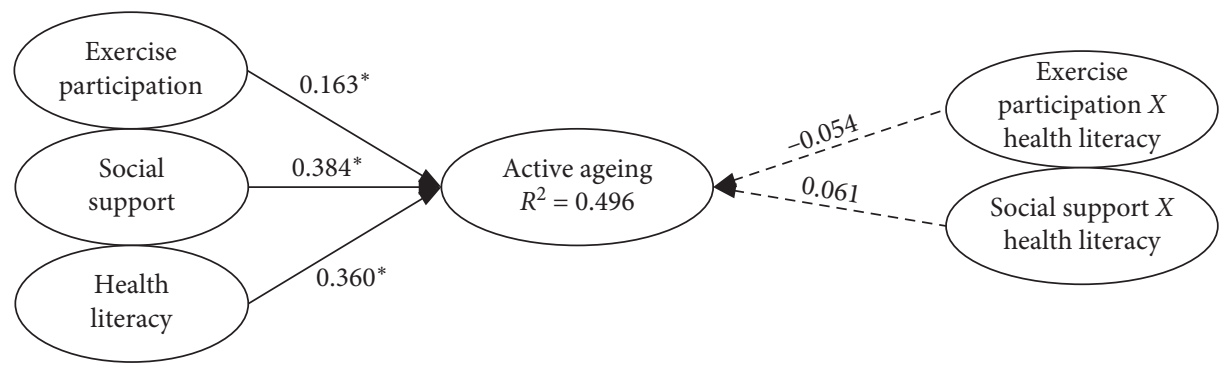

Figure 2: Path coefficients for the research model (including interaction effect). Value on path: standardized coefficients $(\beta) ; R^{2}$ : coefficient of determination; * $*<0.05$

TABLE 3: Estimation results for hypotheses.

\begin{tabular}{|c|c|c|c|c|c|c|}
\hline \multirow{2}{*}{ Construct } & \multicolumn{2}{|r|}{ Model 1} & \multicolumn{2}{|r|}{ Model 2} & \multicolumn{2}{|r|}{ Model 3} \\
\hline & $\beta$ & $t$-value ( $p$ value) & $\beta$ & $t$-value ( $p$ value) & $\beta$ & $t$-value ( $p$ value) \\
\hline Exercise participation $\longrightarrow$ active ageing & $0.171^{*}$ & $7.963(0.000)$ & $0.133^{*}$ & $6.588(0.000)$ & $0.163^{*}$ & $4.079(0.000)$ \\
\hline $\begin{array}{l}\text { Social support } \longrightarrow \text { active ageing } \\
\text { Moderator effect }\end{array}$ & $0.588^{*}$ & $34.234(0.000)$ & $0.399^{*}$ & $18.028(0.000)$ & $0.384^{*}$ & $16.469(0.000)$ \\
\hline $\begin{array}{l}\text { Moderator effect } \\
\text { Health literacy } \longrightarrow \text { active ageing } \\
\text { Interaction effect }\end{array}$ & & & $0.360^{*}$ & $16.472(0.000)$ & $0.360^{*}$ & $16.639(0.000)$ \\
\hline Exercise participation $\mathrm{X}$ health literacy $\longrightarrow$ active ageing & & & & & -0.054 & $1.334(0.197)$ \\
\hline $\begin{array}{l}\text { Social support } \mathrm{X} \text { health literacy } \longrightarrow \text { active ageing } \\
R^{2}\end{array}$ & & & & & 0.061 & $1.741(0.066)$ \\
\hline & & 0.406 & & 0.491 & & 0.496 \\
\hline
\end{tabular}

${ }^{*} p<0.05$

adults might have already integrated exercise into their lives and simultaneously gained a high level of social support, which may explain the nonsignificant moderating effect of health literacy in this study. Furthermore, a unified conclusion has yet to be reached regarding the definition of health literacy. The initial definition of functional health literacy emphasized an individual's ability to understand and express health-related information, both orally and in writing. This definition was later expanded to include communication and critical thinking abilities [28, 29]. Furthermore, scholars have proposed that health literacy further involves scientific literacy, health policy literacy, and cultural literacy [30]. In this study, health literacy was defined as the abilities specified under the conventional definition of health literacy and through an exploratory analysis of the concept of functional health literacy. The factors outlined in the definition may have also contributed to the nonsignificant moderating effect of health literacy in this study.

\section{Conclusions}

A causal model of older adults' exercise participation, social support, and active aging was proposed in this study. The results could be used as a reference for future proposals for relevant institutes and older adults. Exercise participation, 
social support, and health literacy exhibited significant, positive effects on active aging. However, health literacy did not exhibit a moderating effect on the relationships between exercise participation, social support, and active aging in older adults.

\section{Limitations and Further Research}

This study investigated the factors affecting active aging among older adults in Northern Taiwan and outpatients from a target hospital. However, the study was limited by several research constraints. First, this study focused on only older adults in Northern Taiwan (New Taipei City, Taipei City, and Taoyuan City) and older adults recruited from the target hospital. Therefore, the sample population is not fully representative of older adults in Taiwan. Future studies should employ a broader research scope and compare older adults across regions to clarify the differences. Second, this study employed a questionnaire survey to assess respondents' perceptions and awareness of each item. The discussion of this paper only presents a description of the results and comparisons with the results from previous studies; consequently, this paper provides limited insights into the factors influencing older adults' active aging. To address this limitation, researchers should employ qualitative research approaches, such as in-depth interviews, after data analyses to acquire a thorough understanding of older adults' perceptions of this topic and thus obtain more comprehensive research results. Third, only exercise participation and social support were used to discuss active aging in this study. However, active aging is also affected by other factors. Therefore, future studies should include other variables, such as leisure constraints, or expand explorations of health literacy to encompass scientific literacy, health policy literacy, and cultural literacy. Furthermore, several topics in this line of research warrant further discussion.

\section{Data Availability}

No data were used to support this study.

\section{Disclosure}

Chen-Wei $\mathrm{Yu}$ is the joint first author.

\section{Conflicts of Interest}

The authors declare that there are no conflicts of interest regarding the publication of this paper.

\section{Acknowledgments}

The authors thank the Taoyuan Armed Forces General Hospital of Taiwan for financially supporting this research under contract Taoyuan Armed Forces General Hospital: 10719 .

\section{References}

[1] National Development Council, "Population estimation report (2018-2065)," 2014, https://www.ndc.gov.tw/News_Content. aspx? $\mathrm{n}=114 \mathrm{AAE} 178 \mathrm{CD} 95 \mathrm{D} 4 \mathrm{C} \& \mathrm{sms}=\mathrm{DF} 717169 \mathrm{EA} 26 \mathrm{~F} 1 \mathrm{~A} 3 \& \mathrm{~s}=$ E1EC042108072B67.

[2] World Health Organization, "Active ageing: a policy framework," Madrid Spain: Ageing and Life Course Program, Second United Nations World Assembly on Ageing, WHO, Geneva, Switzerland, 2002.

[3] J. W. Rowe and R. L. Kahn, Successful Ageing, Dell Publishing, New York, NY, USA, 1998.

[4] J. W. Rowe and R. L. Kahn, "Successful ageing," Gerontologist, vol. 37, pp. 433-440, 1987.

[5] T. A. Glass, C. F. M. De Leon, S. S. Bassuk, and L. F. Berkman, "Social engagement and depressive symptoms in late life," Journal of Aging and Health, vol. 18, no. 4, pp. 604-628, 2006.

[6] C. J. Caspersen, K. E. Powell, and G. M. Christenson, "Physical activity, exercise, and physical fitness: definitions and distinctions for health-related research," Public Health Reports, vol. 100, no. 2, pp. 126-130, 1985.

[7] N. Teoman, A. Ozcan, and B. Acar, "The effect of exercise on physical fitness and quality of life in postmenopausal women," Maturitas, vol. 47, no. 2, pp. 71-77, 2004.

[8] American College of Sports Medicine, "ACSM position stand: the recommended quantity and quality of exercise for developing and maintaining cardiorespiratory and muscular fitness, and flexibility in healthy adults," Medicine \& Science in Sports \& Exercise, vol. 30, no. 6, pp. 975-991, 1998.

[9] G. Godbey, Leisure in Your Life: An Exploration, Venture, State College, PA, USA, 1999.

[10] G. R. Lee, "Theoretical perspectives on social networks," in Social Support Networks and the Care of the Elderly, J. Sauer and R. T. Coward, Eds., pp. 21-37, Springer, New York, NY, USA, 1985.

[11] C. Schaefer, J. C. Coyne, and R. S. Lazarus, "The health-related functions of social support," Journal of Behavioral Medicine, vol. 4, no. 4, pp. 381-406, 1981.

[12] E. J. Rugel and R. M. Carpiano, "Gender differences in the roles for social support in ensuring adequate fruit and vegetable consumption among older adult Canadians," Appetite, vol. 92, pp. 102-109, 2015.

[13] H. J. Oh, C. Lauckner, J. Boehmer, R. Fewins-Bliss, and K. Li, "Facebooking for health: an examination into the solicitation and effects of health-related social support on social networking sites," Computers in Human Behavior, vol. 29, no. 5, pp. 2072-2080, 2013.

[14] S.-Y. D. Lee, A. M. Arozullah, and Y. I. Cho, "Health literacy, social support, and health: a research agenda," Social Science \& Medicine, vol. 58, no. 7, pp. 1309-1321, 2004.

[15] J. A. Gazmararian, M. V. Williams, J. Peel, and D. W. Baker, "Health literacy and knowledge of chronic disease," Patient Education and Counseling, vol. 51, no. 3, pp. 267-275, 2003.

[16] M. S. Wolf, J. A. Gazmararian, and D. W. Baker, "Health literacy and functional health status among older adults," Archives of Internal Medicine, vol. 165, no. 17, pp. 1946-1952, 2005.

[17] Centers for Disease Control and prevention, "Improving health literacy for older adults," 2009, http://www.cdc.gov/ healthmarketing/healthliteracy/reports/olderadults.pdf.

[18] S. Garbers, K. Schmitt, A. M. Rappa, and M. A. Chiasson, "Functional health literacy in Spanish-speaking latinas seeking breast cancer screening through the national breast 
and cervical cancer screening program," International Journal of Women's Health, vol. 1, pp. 21-29, 2009.

[19] D. P. Miller, C. D. Brownlee, T. P. McCoy, and M. P. Pignone, "The effect of health literacy on knowledge and receipt of colorectal cancer screening: a survey study," BMC Family Practice, vol. 8, no. 16, pp. 1-7, 2007.

[20] K. R. Fox, Physical Self-Perceptions and Exercise Involvement, Arizona State University, Tempe, AZ, USA, 1987.

[21] F. Hair Jr., W. C. Black, B. J. Babin, and R. E. Anderson, Multivariate Data Analysis: A Global Perspective, MacMillan, New York, NY, USA, 7th edition, 2010.

[22] J. F Hair Jr., G. T. M. Hult, C. Ringle, and M. Sarstedt, A Primer on Partial Least Squares Structural Equation Modeling (PLS-SEM), Sage Publications, Thousand Oaks, CA, USA, 2016.

[23] J. C. Anderson and D. W. Gerbing, "Structural equation modeling in practice: a Review and recommended two-step approach," Psychological Bulletin, vol. 103, no. 3, pp. 411-423, 1988.

[24] R. P. Bagozzi and Y. Yi, "Specification, evaluation, and interpretation of structural equation models," Journal of the Academy of Marketing Science, vol. 40, no. 1, pp. 8-34, 2012.

[25] W. W. Chin, "The partial least squares approach to structural equation modeling," in Modern Business Research Methods, G. A. Marcoulides and Mahwah, Eds., pp. 295-336, Lawrence Erlbaum Associates, New Jersey, NJ, USA, 1998.

[26] C. Fornell and D. F. Larcker, "Evaluating structural equation models with unobservable variables and measurement error," Journal of Marketing Research, vol. 18, no. 1, pp. 39-50, 1981.

[27] R. M. Baron and D. A. Kenny, "The moderator-mediator variable distinction in social psychological research: conceptual, strategic, and statistical considerations," Journal of Personality and Social Psychology, vol. 51, no. 6, pp. 1173-1182, 1986.

[28] L. Nielsen-Bohlman, A. M. Panzar, and D. A. Kindig, Health Literacy: A Prescription to End Confusion, National Academies Press, Washington, DC, USA, 2004.

[29] D. Nutbeam, "Health literacy as a public health goal: a challenge for contemporary health education and communication strategies into the 21st century," Health Promotion International, vol. 15, no. 3, pp. 259-267, 2000.

[30] C. Zarcadoolas, A. Pleasant, and D. S. Greer, "Understanding health literacy: an expanded model," Health Promotion International, vol. 20, no. 2, pp. 195-203, 2005. 